\title{
Balancing risks and rewards in assessing pediatric heart disease
}

\author{
Kenneth J. Nichols, PhD, ${ }^{\mathrm{a}, \mathrm{b}}$ Rachel Gecelter, BS, ${ }^{\mathrm{c}}$ and Andrew Van Tosh, $\mathrm{MD}^{\mathrm{c}}$ \\ a Department of Radiology, Donald and Barbra Zucker School of Medicine at Hofstra/Northwell, \\ Hempstead, NY \\ b Division of Nuclear Medicine and Molecular Imaging, Northwell Health, 270-05 76th Avenue, \\ NY \\ c Research Department, St. Francis Hospital, Roslyn, NY
}

Received Jul 30, 2019; accepted Jul 30, 2019

doi: $10.1007 /$ s12350-019-01860-3

\section{See related article, pp. 1395-1408}

This month's issue of the Journal includes an article focusing on diagnosing heart failure in children. ${ }^{1}$ The image that most readily comes to mind of a patient in heart failure is that of a middle-aged or older adult. A patient population was studied of subjects as young as 5 years old who had several types of congenital heart disease (CHD). While the need to evaluate heart failure is not surprising in an elderly subject, it is startling to encounter heart failure in a patient who is only 5 years old. The other unusual aspect of this paper is that investigations related to congenital abnormalities usually involve populations comprised of children, but the subjects studied in this study were not only minors; the oldest patient was 85 years old.

This is an unusual patient population, but not so unusual as to be clinically irrelevant. CHD is the most common congenital birth defect, with an estimated prevalence of 8 per 1,000 live births. ${ }^{2}$ The most common congenital heart lesion is ventricular septal defect, followed by atrial septal defect, patent ductus arteriosus, coarctation of the aorta, Tetralogy of Fallot, and transposition of great arteries. ${ }^{3}$ The etiology of CHD is multifactorial, with most cases attributed to genetic predisposition and environmental factors. A smaller

Reprint requests: Kenneth J. Nichols, PhD, Division of Nuclear Medicine and Molecular Imaging, Northwell Health, 270-05 76th Avenue New Hyde Park, NY 11040, USA; knichols@northwell.edu J Nucl Cardiol 2021;28:1409-12.

$1071-3581 / \$ 34.00$

Copyright (C) 2019 American Society of Nuclear Cardiology. percentage of cases arise from chromosomal abnormalities. ${ }^{4}$

It is in the youngest patients for whom there is the greatest potential for significant improvement in quality of life. Clinicians wish to provide optimum medical care for each patient, regardless of age. By intervening positively at ages as young as 5, there is the prospect of effecting improvements in health to realize many decades of a high quality of life for an individual. But, inevitably, attendant on circumstances with the greatest potential rewards are the greatest potential risks.

All imaging procedures that use ionizing radiation unavoidably deliver radiation dose to patients, and there currently is a concerted effort to reduce diagnostic radiation dose across all patient groups. ${ }^{5}$ Nuclear medicine has a long history of conscientiously limiting the amount of injected activity so as to deliver radiation doses on average that are so low that they are comparable to the amount of dose received by most people due to the unavoidable background radiation. The mean dose that non-occupationally exposed individuals receive is estimated to be $3 \mathrm{mSv}$ per year, while occupationally exposed individuals are allowed by law to receive $50 \mathrm{mSv}$ per year. ${ }^{6}$ For many years, administered activity was limited to deliver less than $50 \mathrm{mSv}$ to the target organ for diagnostic nuclear medicine procedures. More recently the goal has been to limit delivered whole body dose to $10 \mathrm{mSv}$ per imaging session. Some imaging studies have reported modifications of SPECT procedures that have achieved mean dose of only $1 \mathrm{mSv}$ per injection. ${ }^{7}$ For context, the amount of radiation dose was estimated to be $12.5 \mathrm{mSv}$ from SPECT/CT and even less, at only $2 \mathrm{mSv}$, from ${ }^{13} \mathrm{~N}$-ammonia PET/CT, in the current paper.

It is necessary to take into account that the same amount of radiation dose is associated with different 
levels of radiation risks for different types of patients and for different organ systems. Radiation risks specific to children occur at lower dose than in adults. ${ }^{8}$ Furthermore, risk assessments by age and gender have demonstrated that the younger the patient, the greater the radiation risk, as is particularly evident in children requiring multiple $\mathrm{CT}$ examinations prior to undergoing surgical repair for congenital abnormalities. ${ }^{9}$ Because of the young age of many of these subjects, there are compounded risks from radiation effective dose resulting from multiple diagnostic procedures that use ionizing radiation, ${ }^{10}$ which if not closely monitored could become excessive. Triggering the development of leukemia is a particular concern in the youngest patients, as has been seen in pediatric populations requiring multiple CT evaluations because of life-threatening conditions, for whom cumulated dose can reach $100 \mathrm{mSv}^{11}$

Conversely, there are the risks involved with doing nothing if CHD is not addressed. Untreated, even simple CHD causes many deleterious effects, including growth retardation, reduced exercise tolerance, and behavioral abnormalities, all of which require medical therapy and frequent hospitalizations, with poor overall prognosis. ${ }^{12}$ Complex congenital heart lesions have both cardiac and non-cardiac complications. Cardiac complications include bacterial endocarditis, embolic events, arrhythmias, ventricular dysfunction, valvular lesions, hypertension, aneurysms, and eventually heart failure. ${ }^{3}$ Non-cardiac comorbidities include renal, pulmonary, and hepatic dysfunction. For children with Tetralogy of Fallot, only $11 \%$ of un-operated patients are alive by 20 years old and only $3 \%$ by age $40 .{ }^{3}$ Children with transposition of the great arteries rarely survive past childhood without surgical intervention. Developments and improvement in surgical techniques and the interventional catheter-based therapies have led to significant improvements in outcomes for patients with CHD. ${ }^{13,14}$

Thus, a balance must be struck between potential risks versus potential benefits, and in the case of pediatric cardiology this is an area of medicine in which that need is pronounced. Attempting to achieve this balance only by reducing administered activity in conjunction with using conventional imaging technology can be selfdefeating, as that invites the risk of misdiagnosing cardiac disease due to inadequate image quality if so little activity is administered that the reliability of imaging interpretation becomes suboptimal, as signal-to-noise degrades progressively with decreasing image counts.

Nuclear cardiologic techniques were an early contributor to the diagnosis and evaluation of CHD. Maltz et al refined a radionuclide angiocardiography technique to non-invasively estimate shunt fraction using first-pass time activity curves. ${ }^{15}$ Equilibrium radionuclide angiography was used to demonstrate that in patients who had the Mustard procedure for D-transpositions, right and left EF was normal but failed to increase with maximal exercise, a pattern that persisted over 4 years of subsequent follow-up. ${ }^{16}{ }^{201} \mathrm{Tl}$ SPECT myocardial perfusion imaging evaluated patients who had D-transposition treated with the arterial switch operation, finding $43 \%$ of patients demonstrated fixed or reversible defects. ${ }^{17}{ }^{99 \mathrm{~m}}$ Tc-MIBI SPECT showed that $25 \%$ of patients exhibited myocardial perfusion defects several years after the arterial switch operation. ${ }^{18}$ Abnormal coronary flow could contribute to the late development of reduced cardiac function post-op and to sudden cardiac death. ${ }^{17,18}$ Contemporaneous catheterization studies confirmed that some patients have coronary stenoses following the arterial switch procedure, with rare instances of late mortality and sudden death. ${ }^{19}$

While advances in cardiac CT have enabled evaluating the anatomic course and potential obstructions of aberrant coronary arteries,${ }^{20}$ a role persists for myocardial perfusion imaging in $\mathrm{CHD}$, particularly in clinical situations in which angina or myocardial ischemia are suspected. $^{21,22}$ Improved outcomes of CHD patients have fostered long-term survival, such that conventional coronary risk factors may produce atherosclerotic cardiovascular disease. A review of patients with CHD who developed symptomatic coronary disease found that most patients had significant coronary risk factors, and that patients with coarctation of the aorta tended to present at an earlier age, attributable to sustained hypertension, which is common in this group. ${ }^{23}$ Some categories of CHD are associated with abnormalities of the coronaries,${ }^{24}$ or inadequate coronary flow, ${ }^{25}$ either as a primary syndrome, or as a sequelae of the curative surgery.

The current article explored the ways in which recent technological advances have enabled a rebalancing of risk-benefit ratios, suggesting which particular nuclear cardiology imaging approaches have now become advantageous for younger patients who require multiple repeated imaging evaluations. The case is made for tailoring procedures with the age of the subjects in mind: predictably, estimated radiation dose was higher in those children who were administered the same activity as an adult as opposed to those for whom weight-based activity administration was used.

In the current study, radiation dose was estimated rather than measured. That is understandable, as the logistics of directly measuring radiation dose are challenging. ${ }^{26}$ While CT scanners can incorporate sensors to produce reasonable estimates of entrance dose to the skin, the organ receiving the highest dose from CT imaging, target organs that receive the maximum dose from administration of radiopharmaceuticals are 
inaccessibly internal (bone marrow, liver, kidneys, etc.) and delivered organ radiation dose depends on which particular radiopharmaceutical is used. ${ }^{27}$ Organ doses are estimated for patients in general, not assessed individually on a patient-by-patient basis. Efforts are ongoing to combine PET with CT scans to produce a detailed map of radiation dose delivered to individual organs for individual patients for radiotherapy procedures such as ${ }^{131}$ I therapy for thyroid cancer. ${ }^{28}$ But these approaches are only now in the research phase, and the ability to attempt anything comparable for pediatric nuclear cardiology studies must await future developments.

While refining actual delivered radiation dose to each individual patient will require further future innovations, the technological advances of the past few years already have afforded considerable improvements in dose reduction and expansion of the options that are now currently available, and that is the focus of the investigation by Partington et al. ${ }^{1}$ For hybrid imaging procedures, radiation dose for the $\mathrm{CT}$ component can be limited by employing newer software that enables estimating CT radiation dose prior to choosing a particular CT protocol for a younger patient, allowing clinicians to determine the likely differences that would result from different choices of CT settings. As for SPECT imaging procedures, in an imaging laboratory that has both types of equipment, it would be preferable to use CZT cameras as opposed to conventional NaI(Tl)-based Anger detectors for pediatric cases in order to enable injecting a lower amount of activity to achieve the same count rate. $^{29}$ Technical advances in SPECT systems have resulted in greatly enhanced machine sensitivity and spatial resolution. ${ }^{30}$

Also, consider the ${ }^{13} \mathrm{~N}$-amonia PET/CT procedures that are discussed in the current paper. The radiopharmaceutical was already well suited to pediatric nuclear cardiology due to its delivering low radiation dose by virtue of its rapid washout and short half-life. What inhibited a more wide-spread usage of this agent was that until recently it was necessary to have in-house a major cyclotron, or be fortunate enough to be located within only a few miles of a facility. But now, deploying ${ }^{13} \mathrm{~N}$-amonia PET more widely is becoming more feasible as compact superconducting cyclotrons that generate individual amounts of injectate on an "as-needs" basis have become available for purchase or lease. Also, technical improvements in the PET scanners used to produce the perfusion images are much more sensitive than previously. Replacing 2D PET with 3D PET, implementing time-of-flight electronics and replacing conventional photomultiplier tubes all have produced higher-count, higher-sensitivity, and higher signal-tonoise ratio images than have previously been possible.
These PET imaging innovations have advanced rapidly, with improvements in detector designs and electronics going hand-in-hand with developments in computer science and image modeling that have vastly improved and accelerated reconstruction algorithms. Furthermore, efforts are underway to replace the CT component of PET/CT, with its own unavoidable radiation dose delivery, with MRI; studies already are underway to define optimal amounts of tracer activity to administer in conjunction with PET/MRI technology for pediatric evaluations. $^{31}$

In summary, the article by Partington et al makes several important points. The prevalence of abnormal myocardial perfusion and ischemia findings among patients with CHD is quite high, and considering the seriousness of these and related deleterious conditions, it is important to monitor patients with CHD and intervene medically in an effective manner. The delivery of radiation dose in the process of evaluating such patients is unavoidable, but it is possible to balance the long-term risks of radiation exposure in children with the benefits of accurate diagnostic information by means of the technical advances that have enabled highly accurate evaluations while limiting radiation dose. This article by Partington et al provides valuable guidance for achieving this balance.

\section{Disclosure}

Kenneth Nichols participates in royalties from Syntermed, Inc.; Andrew Van Tosh serves as a consultant to Astellas Pharma Global Development, Inc.

\section{References}

1. Partington SL, Valente AM, Bruyere J, Rosica D, Shafer K, Landzberg $\mathrm{M}$, et al. Reducing radiation dose from myocardial perfusion imaging in subjects with complex congenital heart disease. J Nucl Cardiol 2019. https://doi.org/10.1007/s12350-01901811-y.

2. van der Linde D, Konings E, Slager M, Witsenburg M, Helbing $\mathrm{W}$, Takkenberg J, et al. Birth prevalence of congenital heart disease worldwide. JACC 2011;58:2241-7.

3. Kliegman R, Stanton B, St. Geme J, Schor N, Behrman R, Nelson W. Nelson textbook of pediatrics. 20th ed. Philadelphia: Elsevier; 2016.

4. Blue G, Kirk E, Sholler G, Harvey R, Winlaw D. Congenital heart disease: Current knowledge about causes and inheritance. Med J Aust 2012;197:155-9.

5. Hirshfeld JW, Ferrari VA, Bengel FM, Bergersen L, Chambers CE, Einstein AJ, et al. 2018 ACC/HRS/NASCI/SCAI/SCCT expert consensus document on optimal use of ionizing radiation in cardiovascular imaging: Best practices for safety and effectiveness. Catheter Cardiovasc Interv 2018;92:E35-97.

6. https://www.nrc.gov/about-nrc/radiation/around-us/.

7. Einstein AJ, Blankstein R, Andrews H, Fish M, Padgett R, Hayes $\mathrm{SW}$, et al. Comparison of image quality, myocardial perfusion, and 
left ventricular function between standard imaging and single-injection ultra-low-dose imaging using a high-efficiency SPECT camera: The MILLISIEVERT study. J Nucl Med 2014;55:1430-7.

8. Little MP. Heterogeneity of variation of relative risk by age at exposure in the Japanese atomic bomb survivors. Radiat Environ Biophys 2009;48:253-62.

9. Glatz AC, Purrington KS, Klinger A, King AR, Hellinger J, Zhu $\mathrm{X}$, et al. Cumulative exposure to medical radiation for children requiring surgery for congenital heart disease. J Pediatr 2014;164:789-94.

10. Hill KD, Frush DP, Han BK, Abbott BG, Armstrong AK, DeKemp RA, et al. Radiation safety in children with congenital and acquired heart disease: A scientific position statement on multimodality dose optimization from the image gently alliance. JACC Cardiovasc Imaging 2017;10:797-818.

11. Pearce MS, Salotti JA, Little MP, McHugh K, Lee C, Kim KP, et al. Radiation exposure from CT scans in childhood and subsequent risk of leukaemia and brain tumours: A retrospective cohort study. Lancet 2012;380:499-505.

12. Green A. Outcomes of congenital heart disease: A review. Pediatr Nurs 2004;30:280-4.

13. Khairy P, Ionescu-Ittu R, Mackie AS, Abrahamowicz M, Pilote L, Marelli AJ. Changing mortality in congenital heart disease. J Am Coll Cardiol 2010;56:1149-57.

14. Gilboa SM, Salemi JL, Nembhard WN, Fixler DE, Correa A. Mortality resulting from congenital heart disease among children and adults in the United States, 1999 to 2006. Circulation 2010;122:2254-63.

15. Maltz DL, Treves S. Quantitative radionuclide angiocardiography. Determination of Qp:Qs in children. Circulation 1973;47:1049-56.

16. Hochreiter C, Snyder MS, Borer JS, Engle MA. Right and left ventricular performance 10 years after Mustard repair of transposition of the great arteries. Am J Cardiol 1994;74:478-82.

17. Vogel M, Smallhorn JF, Gilday D, Benson LN, Ash J, Williams WG, et al. Assessment of myocardial perfusion in patients after the arterial switch operation. J Nucl Med 1991;32:237-41.

18. Hayes AM, Baker EJ, Kakadeker A, Parsons JM, Martin RP, Radley-Smith R, et al. Influence of anatomic correction for transposition of the great arteries on myocardial perfusion: Radionuclide imaging with technetium-99 m 2-alethoyly isobutyl isonitrile. J Am Coll Cardiol 1994;24:769-77.

19. Tanel RE, Wernovsky G, Landzberg MJ, Perry SB, Burke RP. Coronary artery abnormalities detected at cardiac catheterization following the arterial switch operation for transposition of the great arteries. Am J Cardiol 1995;76:153-7.

20. Bernsen MLE, Koppes JCC, Straver B, Verberne HJ. Left ventricular ischemia after arterial switch procedure: Role of myocardial perfusion scintigraphy and cardiac CT. J Nucl Cardiol 2019. https://doi.org/10.1007/s12350-019-01738-4.

21. Kondo C. Myocardial perfusion imaging in pediatric cardiology. Ann Nucl Med 2004;18:551-61.

22. Partington SL, Valente AM, Landzberg M, Grant F, Marcelo F, Di Carli MF, Dorbala S. Clinical applications of radionuclide imaging in the evaluation and management of patients with congenital heart disease. J Nucl Cardiol 2016;23:45-63.

23. Yalonetsky S, Horlick EM, Osten MD, Benson LN, Oechslin EN, Silversides CK. Clinical characteristics of coronary artery disease in adults with congenital heart defects. Int $\mathrm{J}$ Cardiol 2013;164:217-20.

24. Bonnet D, Bonhoeffer P, Piechaud J-F, Aggoun Y, Sidi D, Planche $\mathrm{C}$, et al. Long-term fate of the coronary arteries after the arterial switch operation in newborns with transposition of the great arteries. Heart 1996;76:274-9.

25. Hauser M, Bengel FM, Kühn A, Sauer U, Zylla S, Braun SL, et al. Myocardial blood flow and flow reserve after coronary reimplantation in patients after arterial switch and Ross operation. Circulation 2001;103:1875-80.

26. Yakoumakis EN, Gialousis GI, Papadopoulou D, Makri T, Pappouli Z, Yakoumakis N, et al. Estimation of children's radiation dose from cardiac catheterisations, performed for the diagnosis or the treatment of a congenital heart disease using TLD dosimetry and Monte Carlo simulation. J Radiol Prot 2009;29:251-61.

27. Zvereva A, Kamp F, Schlattl H, Zankl M, Parodi K. Impact of interpatient variability on organ dose estimates according to MIRD schema: Uncertainty and variance-based sensitivity analysis. Med Phys 2018;45:3391-403.

28. Dewaraja YK, Frey EC, Sgouros G, Brill AB, Roberson P, Zanzonico PB, et al. MIRD pamphlet no. 23: Quantitative SPECT for patient-specific 3-dimensional dosimetry in internal radionuclide therapy. J Nucl Med 2012;53:1310-25.

29. Duvall WL, Croft LB, Ginsberg ES, Einstein AJ, Guma KA, George $\mathrm{T}$, et al. Reduced isotope dose and imaging time with a high-efficiency CZT SPECT camera. J Nucl Cardiol 2011;18:84757.

30. Slomka PJ, Patton JA, Berman DS, Germano G. Advances in technical aspects of myocardial perfusion SPECT imaging. J Nucl Cardiol 2009;16:255-76.

31. Branchini M, Zorz A, Zucchetta P, Bettinelli A, De Monte F, Cecchin D, et al. Impact of acquisition count statistics reduction and SUV discretization on PET radiomic features in pediatric 18FFDG-PET/MRI examinations. Phys Med 2019;59:117-26.

Publisher's Note Springer Nature remains neutral with regard to jurisdictional claims in published maps and institutional affiliations. 